\title{
8.5 Technique of development and teaching a subject matter at the higher school
}

Lecturing technique. A lecture is the main form of carrying out studies in higher education institution which is intended for assimilation of theoretical material. As a rule, the lecture covers the main theoretical material of one or several topics of a subject matter. The subject of lecture course is defined by the working training program. Giving of problematic lectures which content concerns this discipline is possible, but it is not covered by the training program. Such lectures are given by the leading specialists scientists for students and employees of higher education institutions in specially allotted time. Lectures are given by professors and associate professors (tutors) of higher education institution. In exceptional cases lecturing is allowed for teachers after the corresponding decision of department [595, 597, 602].

The lecturer, who is entrusted to give a course of lectures, is obliged to provide the abstract of lectures (author's textbook, the manual) to the department before the corresponding semester, as well as control tasks for carrying out the final control provided by the curriculum and the program for this discipline. The lecturer is obliged to follow to the training program on subjects of lecture classes, but not to be limited in matter of interpretation of a training material, forms and ways of bringing it to students [596, 600, 606].

The lecture with elements of problem training begins not with the announcement of a subject of a lecture, but with creation of a problem situation for students, solving of which together with audience, the lecturer immerses the listeners in the world of knowledge of new information. After it was succeeded to formulate a problem, it needs to be structured to 2-3 problematic issues (in ordinary lectures it is equivalent to the main questions of a lecture). Now each problem has to be formulated independently. The quantity of problematic issues depends on the maintenance of a problem and ability of the teacher to separate information for independent "portions" of the completed information. Each problem has to be accurately formulated. After structuring a problem, single problematic issues are placed in the sequence determined by the importance in which the solution of one problem would promote statement of 
following. The sequence of problem situations which is developed presents the plan of a lecture in its traditional understanding [598, 599, 601].

Preparation for a performance at a lecture. Oratorical and pedagogical art is a mean of influencing people and at the same time a mean to manage them. Success comes if we consider the interests of people, their psychological features, requirements, perception and understanding of a situation. The oratory is an art of preparation to the speech with a concrete impact on mind, feelings and will of listeners [603, 607].

The main rule of the lecturer is to know what, where and how to tell. The famous Roman speaker Mark Tully Cicero in his work "On the Orator" noted that for achievement of the goal during the speech the speaker has to do three things: 1) it is persuasively to prove the ideas; 2) to affect will and feelings of listeners; 3 ) to give pleasure to audience. Therefore, success of a public performing, as well as thousands years ago, depends on knowledge of methods of oratory, the standard of speech and continued work. Let's remind an oratory precept: "Are born poets, and become speakers" [604].

The good speech is very often compared to the growing tree where a root is incentive motive, a trunk is the main issue and branches are auxiliary questions, leaves - comparison, flowers - rhetorical methods [605].

The effectiveness of a lecture depends on many factors, in particular on a situation in which it is given; type of audience with which the teacher works; individual qualities of the lecturer and others. Sign of the effective and successful lecturer who is able to work with audience is the ability to use a set of styles and genres of performances, all methods of impact on audience in the work, ability to adapt quickly in a new situation $[608,612,619]$.

The lecture should be considered not only as information passing from the teacher's head to the student's head. First of all, the lecture is: mean of exchanging opinions; mean of polemic (discussion) form of educational managing and creative activity of students. In this context there is a very important question; what is the oratorical skill of the teacher defined by? First of all the charisma level, the outstanding personality of the speaker, ability to influence audience, to interest students in the 
practical value of a subject, the standard of speech. At the same time full-time employment and improvement lecturing skill is a condition of a good result [609].

The more we will consider the interests of students, features of their perception of information, the level of readiness, requirement - the more chances the lecturer has for the success. A basis of it is the ability to own a word, teacher's ability to convince people. Successful mastering lecturing skill is promoted by studying experience of the best speakers, critical estimation of own experience and aspiration to self-improvement [596, $598,610]$.

According to contents and data representation form of a lecture is divided into the following types: problematic, informational, summarizing, consulting (survey), and as their given to listeners - monologues (without emphasis on reaction of audience) dialogues (continuous interaction with listeners) discussions (disclosure of contradictions during the lecture) [613].

\section{Training of the speaker for a lecture performance.}

This preparation includes the following stages [611]:

$\checkmark$ definition of type of a performance which can be: informational (gives the concrete description, the found regularity, offers certain results) propaganda (it is necessary to convince audience, to inspire, recruit, etc.); combinational;

$\checkmark$ choosing of a performance stile which can be: scientific (it is characterized by the reasonable argument and academism) business (it is used among businessmen, practicians) an interview (confidential conversation of the curator with audience)

$\checkmark$ definition of the speech variants: a) to read from the abstract, b) to reproduce on memory, c) to state freely or to improvise. Depending on type and a way of preparation the option of reading a lecture is chosen individually

$\checkmark$ definition of an accurate lecture of composite construction (introduction, main part, conclusion). 
At the same time, it is necessary to remember a psychological component of assimilation of information by students depending on a form of representation of information material. For example, if students perceive evident material then the visual memory works, perceive information aurally - acoustical memory, entering polemic they begin to argue. By many researches it is established that for increase in efficiency of perception of information the lecturer needs to use an integrated approach [614].

The teacher composes each next lecture material around the main idea ("main base"). It is desirable that the training material of one lecture could be sorted for 2 class periods (one couple) with its logical conclusion. During preparation for a performance it is necessary to remember that for increase in efficiency of assimilation of a training material it is necessary to observe the following requirements [605]:

- the average length of the sentence should not be more than 15 words;

- there has to be a variety in offers;

- it is desirable to put quite developed thought in one point;

- use the standard reductions;

- use evident graphic means of submission of information;

- revise the text several times and reduce it whenever is possible.

Psychologists note: there are three memorizing types of a training material for students: 1) direct reflection of sensory (sensual) information; 2) short-term; 3) longterm storing [607].

The teacher has to learn to polemize. Need of conducting discussions arises owing of disagreement in estimates and opinions on any given questions. The teacher needs to consider that students sometimes seek to disprove what is proved by the lecturer. For this purpose, it is necessary to be able to prove the truth.

\section{Reading lecture}

In a lecture the sense is defining. The speech should not be difficult. It is necessary to speak simply, convincingly, frankly, clear. Depending on the purpose of a lecture the structure and a method of material supply is adjusted, the plan is specified, necessary arguments are selected. Experienced lecturers seek to consider structure beforehand, level and the interests of listeners, their mood and possible reaction [602]. 
In a basis of a lecture, stated by means of a method of "main base", the principles of basic accumulation on each question of the most important material are put for the purpose to increase in performance of training process.

Basic principles of this method: material statement in big temporary "portions"; repetition stated several times; feedback from audience in the form of discussion of material [599].

For realization of these principles it is necessary that each next lecture began with the short informative review of earlier stated lecture material - quizzes, for assessment of entrance control of knowledge and full assimilation of information. It takes about 5-7 minutes.

The technology of holding quizzes is formed of short questions with a possibility of prompt replies. At the same time, it is expedient to encourage students with rating points for the correct answers.

The option when the teacher suggests students to prepare quizzes with their own before each lecture in turn is possible.

Psychologists define that in the lecturer there are three fixed assets of impact on audience $[614,618]$ :

- linguistic (contents of the speech);

- paralinguistic (speed, intonation, modulation of a voice, etc.);

- kinetic (gestures, mimicry, poses of the speaker).

While giving of lecture material mind grammatical norms and word usage. Avoid bureaucracy, formulaic - they complicate perception of information and quite often confuse listeners.

Appropriate speech speed is 120 words per $1 \mathrm{~min}$.

Significantly the content of a performance is influenced by pauses. On many researches of a pause make 10-15\% of time of the lecturer speech. Pauses during the performance are different: a breathing pause, grammatical (it is used for attentive reading of text information), pedagogical (for judgment and assimilation of information by listeners) "Full of holes" (the lecturer lost the point, forgot information or does not know what to tell further) [612]. 
General recommendations for the lecturer: try not to read, and to speak; logically express thoughts and offers; define the sequence and consistency of judgments; select the reasoned facts and proofs; be in good mood and friendly; pay attention to erudition; control audience be able to distinguish the critical moments of a lecture, analyze the performance [600].

\section{Technique of carrying out laboratory works.}

Laboratory works are one of forms of studies and one of practical methods of training in which the educational objectives are achieved at statement and carrying out experiments by pupils, researches with use of the special equipment, devices, use of special tools and other technical devices. At these classes the pupils perceive, observe, investigate natural phenomena, technological and other processes, study equipment objects, the device and the principle of operation of measuring and other equipment, a measurement technique $[603,611]$.

The subject and the purpose of laboratory works depend on specifics of specialty, a subject matter and a subject. At the same time, laboratory works perform also the general functions on achievement of the education goals, have extra-subject value at training of specialists.

Thus, introduction of laboratory works to educational process allows to carry out connection of the theory with practice, develops creative and independent activity of pupils, forms skills of use of the modern equipment, measuring and other technical devices and statements and carrying out experiments. At laboratory works the students join in process of knowledge of physical, chemical and other phenomena, being directly involved in carrying out various experiments. Carrying out laboratory works allows to form skills of work with devices, the equipment, assembly and installation of schemes, devices, use by the measuring equipment. Laboratory works contribute to the development of the general abilities to replenishment of knowledge the new facts, data of objects and the phenomena, learn to understand and apply these data, to analyze, synthesize and estimate the received results $[616,619]$. 
Laboratory works play a large role in achievement of the educational purposes at the level of specialty and also the didactic and developing purposes of subject matters and their components.

On the basis of activity approach to the analysis of laboratory works in their structure are allocated the following stages [617]:

- introduction and motivational;

- operational and informative;

- control and estimated;

-final.

The introduction and motivational stage includes definition and the message of a subject of laboratory work, formation of its didactic purpose and motivation of the purpose.

The central stage of laboratory work is operational and informative. It includes preparation for performance of practical tasks and their performance. By preparation for the lesson the teacher forms the list of practical tasks and also a technique of updating of basic knowledge and modalities of action, projects a technique of formation of the approximate basis of activity (ABA) and the organization of carrying out laboratory work. When carrying out laboratory work at this stage the list of tasks is submitted to pupils, basic knowledge and ways of action are updated, ABA is formed, implementation of the didactic project of a stage of work, performance of laboratory tasks by pupils will be organized [615].

At a stage of control and assessment the students carry out processing of experimental data and results of performance of laboratory tasks and also formulate conclusions.

The final stage includes registration and delivery of the report.

Though the specifics of laboratory work as form of lessons is defined by the central operational and informative stage, and other components have auxiliary character, it does not decrease their value for achievement of the goal of educational lesson. 
The structure of laboratory works defines the plan of holding such classes [615, 616]:

- the organization class beginning;

- announcing of a subject, purpose, tasks and motivation of the purpose;

- updating of basic knowledge;

- induction and acquaintance to the instruction;

- performance of tasks, exercises or tests, calculation of results;

- formation of conclusions and execution of the report;

- delivery of the report and assessment of results of work.

Classification of laboratory works is carried out depending on specifics of the tasks solved on occupation. It is allocated introductory, experimental and problematic researching works. At introductory laboratory works the it is held the studying of design features, devices of production mean of activity (equipment, tools, devices, etc.) and means of research activity (installations, devices, etc.) and also their control is carried out [602, 609, 616].

Experimental laboratory works surely include experimental research tasks. They can include tasks on study and working off a technique of carrying out various researches (for example, studying a technique of field experiment), on designing, redesigning and designing of various schemes and devices (for example, drawing up electric circuits for measurement of properties of objects, change of a design of the gear transmission for a variation of transfer number, etc.), on carrying out experiments which purpose is their carrying out, on studying influence of various factors on measurement of properties of objects, by definition of degree of compliance of experimental and design data, on checking, an illustration confirmation of laws and regularities (for example, a research of influence of biological medicines on development of mushroom diseases of plants, etc.) $[610,614,619]$.

Problematic and research works also include statement and carrying out an experiment. They differ only in degree of problematical character of an experimental task. At the same time, it is about levels of problematical character of these tasks for students: about novelty of objects, conditions in which the experiment is made, in 
comparison with studied earlier (theoretically and practically). Laboratory works on check of various hypotheses of educational and scientific level belong to this group of laboratory works [608].

Laboratory works is a form of studies and practical methods of training in which the educational objectives are achieved at statement and carrying out by students, experiments, researches with use of the special equipment, devices, measuring tools and other technical devices (laboratory works) and during the performing of settlement and other types of tasks and the solution of tasks (practical training). On such classes the students work practical actions and skills. For example, at laboratory works they observe, investigate natural phenomena, technical and other processes, study equipment objects, the device and the principle of operation of the measuring equipment, a measurement technique [617].

The scope of laboratory and practical works is determined by the training program by discipline, is concretized for each specialty in the working program for disciplines depending on specifics and the direction of training of specialists, the hours allocated for a workshop in the curriculum and existence of necessary laboratory base. At the same time, firstly the plan of work is done, the most significant for professional training and formations of practical modalities of action.

The wording of the name of work have to include necessary components of structure of the main objective solved at classes that is an object, subject of research; and also its task. At the same time an object, subject or its tasks have to be new to students.

Pay attention that as laboratory and practical works represent forms of studies, their purpose is to change the identity of the student. In cognitive area of structure of the students' identity these changes can be characterized by standards of educational actions with the indication of level of their formation according to taxonomy of the purposes. The motivation of the purpose of works is most often carried out by disclosure practical, professional value of result of work, ensuring interest in a subject, the organization of competitiveness when performing tasks [597, 602]. 
When performing laboratory works various types of algorithms of performance of tasks can be used [613]:

-reproduction algorithm;

- recognition algorithm;

- problem method.

When holding laboratory researches it is necessary to pay attention to their organization. It can differ depending on a form of their carrying out: frontal, cyclic, individual, and a practical training is given the most often by a frontal method. The organization of laboratory work includes also preparation of material resources: objects and means of educational activity.

\section{Technique of carrying out practical and seminar training.}

Practical class is a form of educational class on which the teacher will organize detailed memorizing by students of separate theoretical provisions of a subject matter, therefore skills of practical application of knowledge of theoretical material by individual performance by students of the corresponding tasks are formed [610].

Practical training is given according to the developed thematic plan and covers all material. The list that a practical training is defined by the working training program of discipline. Holding practical class is based on previously prepared methodical material (tests for identification of level of knowledge of students), practical tasks of varying complexity; evident material; methodical instructions. The mentioned methodical providing is prepared by the teacher, it is entrusted to them to give a practical training, in coordination with the lecturer of discipline [615].

Practical class includes carrying out preliminary control of knowledge of students, statement of a common problem by the teacher and its discussion, the solution of tasks with their discussion and assessment of results. The estimates received by the student on a separate practical training are considered at exposure of total assessment on discipline.

Practical occupation has to be formed according to the following scheme: the purpose, basic data, methodical instructions, an algorithm of the decision, a task for independent work (by analogy with the method considered earlier), control questions 
to students for fixing of material, assessment of level of formation of abilities, discussion of the course of training and a question to the teacher, the edition of homework to students [617].

In structure of class independent work dominates. The teacher participates at a problem statement stage, when developing methodical recommendations and exercises control. At the same time practical work can be organized by means of computers when performing tasks on optimization and with use of specialized application programs.

Practical classes can be given in the form of settlement work, a business or didactic game, the analysis of production situations, work with documents, a colloquium, a discussion, an examination. Here is given a form of the plan abstract of practical class which the teacher can use for his preparation [596, 602, 603, 609].

\section{PLAN ABSTRACT OF PRACTICAL CLASS IN DISCIPLINE:}

Class subject:

Date:

Class purposes:

Main problem of training:

Equipment (list of visual aids, posters, etc.):

The plan of training (list of the main points and time which is allowed for their realization):

Training course (detailed abstract):

stages and types of students' activity with constant structure;

formulation of tasks to students at each stage of class;

results of performance of the tasks provided;

references to materials on a training subject (numbering of pages of manuals, etc.);

drawings, tasks (with the decision), schemes, tables, etc.

Task to students from a reflection of their activity;

Forms of control and assessment of results of occupation;

Homework;

The list of the used literature; 
Form of the analysis of the given classes, results of its discussion with colleagues and teachers.

\section{Technique of holding seminar training.}

Seminar training - a form of educational occupation on which the teacher will organize a discussion on previously defined subjects. Students prepare theses of performances on the basis of individually performed tasks (papers) for classes. The list of seminar classes is defined by the working training program of discipline. On each seminar class the teacher estimates the prepared performances, activity of students at discussions, ability to formulate and defend the position. The teacher includes total estimates for each seminar occupation in the register [612].

Model of seminar class in an active form (SAF)

Training of creatively gifted experts of various spheres of production is impossible without activization of forms and methods of educational process. One of the main forms of practical preparation is seminar class which needs to be constructed in an active form of process of effective assimilation by students of educational information on model of management their educational and creative activity, thereby having intensified process of training [605].

The purpose of holding a seminar in an active form (SAF) is to intensify process of thinking of students by direct attraction them to the organization and the managements of occupation. This didactic form is also intended to create and set abilities of collective preparation, justification, adoption and assessment of management decisions, is an obligatory element of creative formation of heads and experts of the production sphere.

The active form of work assumes high-quality changes in relationship between teachers and students: not only the teacher and the corresponding educational and scientific literature, but also audience becomes a source of information. Students from object of management become subjects, in this case they teach each other. The teacher creates such didactic system at which pupils will independently organize holding educational occupation, performing not only retranslation functions on information transfer, but also develop a control algorithm of educational and creative activity, 
provides the general increase in efficiency of process of assimilation of knowledge and formation of creative experience of the personality. At the same time the relation of teachers with students become the subject - subject [614].

Modeling of specific situations is the cornerstone of carrying out SAF (production, social, economic, political). For future managers the active form of education is the most effective not only in the context of acquisition of skills of relationship in manufacturing execution system, but also for identification of reserves of improvement of methods and style of the management.

\section{Order of preparation and holding seminars in an active form (SAF)}

SAF includes two parts: preparatory and the main. Stages of a preparatory part (the teacher together with students carries out):

Acquaintance with a subject of seminar class.

Appointment of the leader (from among students) seminar class and the arbitrator for the leader (also from among listeners)

Development of seminar occupation by the host of regulations.

The first two stages are carried out by the teacher in advance, that is before holding seminar class (for example, at the end of the previous class). The regulations of seminar class are developed by the leader in advance and independently for that he has to get acquainted attentively with a subject of seminar class and study questions which have to be considered according to its plan.

Duration of time of a performance $(t)$ on a question depends on its complexity and the importance and also on the volume of material which needs to be considered according to the plan of seminar class. After drawing up regulations the leader in advance (prior to seminar class) tells speakers time which is allowed for the report. The leader is granted the right to appoint speakers on a subject of seminar class and also arbitrators on each speaker. At the same time each student for one question can be a speaker, and on another - the arbitrator $[609,616]$.

Seminar class in an active form will be organized and held by students. Its feature is that listeners estimate the actions independently, motivating and justifying the made 
decisions. The teacher gives an assessment to work of participants of seminar class (leader, speakers, arbitrators) at the end of class when summing up.

Seminar class in an active form assumes existence of the game moments, is reached by means of creation and support of "game mood". The game situation is set by the leader who has to have the corresponding abilities of the organizer and leadership skills. He has to plan, prepare and hold creatively a seminar that during all class the interest of audience did not weaken $[601,603,605]$.

\section{Functions and role of students when carrying out SAF}

The list of participants - students of the academic group from among whom are allocated: leader of a seminar; the arbitrator for the leader; speakers (the number of speakers has to be not less quantity of questions of the considered subject) arbitrators for speakers.

Functions of the leader. The main part of seminar class (after the previous recommendations of the teacher) begins with an opening speech of the leader. The leader has to report a seminar subject, to call issues which will be discussed, to make short introduction. After that he calls the name a question which will be considered, a surname of the speaker, reports acting regulations, calls the arbitrator on a question. After the end of a speech of the speaker the leader will organize dialogue in form of "question-answer", and then discussion of the report. After that the leader gives the word to the arbitrator who acquaints listeners with estimates of the students who were taking part in discussion of a question. Further the leader sums up the results, and then passes to discussion of the following question of seminar class [606].

After consideration and discussion of all questions of a subject of seminar occupation the leader sums up the general results by short generalization of all considered questions, focusing attention of audience on the key moments of a subject. After that gives the floor to the arbitrator and the teacher.

Functions of the arbitrator on the speaker. The arbitrator has to be guided well in a question on which it gives assessment review. Special attention of the arbitrator has to be paid to disclosure of maintenance of a question. If the speaker opened questions not completely or made mistakes (the passed highlights), then the arbitrator 
has to draw to it the attention of audience and make the relevant amendments and additions.

Functions of the arbitrator for the leader. The arbitrator for the leader estimates his performance on the specified scale. At the same time the leading SAF is estimated by two criteria: 1) for preparation and the organization of seminar occupation; 2) for holding occupation. The special attention of the arbitrator has to be concentrated on ability of the leader to organize discussion of all questions in order that the plan of seminar occupation was implemented completely [605].

In the course of holding seminar class an assessment of actions of participants is given by students, and at the end of class (when summing up) to the teacher.

Individual educational classes are given with certain students for the purpose of increase in level of their preparation and disclosure of individual creative abilities. Individual classes will be organized according to the schedule of the individual curriculum of the student and can cover a part or full volume of classes in a certain discipline, and in some cases the full volume of studies for concrete educational or qualification level [616].

Consultation - a form of educational class at which the student receives the answers or an explanation from the teacher on specific questions of certain theoretical provisions and aspects of their practical application. Consultation can be individual or be carried out for a group of students. Time volume given to the teacher for carrying out consultations on concrete discipline is defined by the curriculum. As a rule, it is 2 class periods. 